tion. The patient soon lcarned to swallow liquids by holding the head well back, and was discharged at the end of the second week. Two weeks ago a small recurrence was noted on the portion of the alveolar process which had been left. This had appeared suspicious at the time of operation, but it. was left behind in the hope that it would be of use when the time came to fit an appliance to take the place, in a measure, of the missing palate and teeth. Under cther, the remaining molar tecth and this portion of the alveolar process were removed. The patient now felt better than he had in the past eighteen months and had gained considerable weight, although limited to fluid and soft diet. While his speech was naturally much interfered with, he could easily make himself understood.

\title{
SIMPLE FRACTURE OF THE CARPAL SCAPHOID.
}

Dr. Wrelum $A$. Downes read a paper with the above title for which see page. 72. In conncetion with his paper, Dr. Downes showed a number of patients and radiographs illustrating fracture of the carpal scaphoid.

DR. Josepir A. Blake asked Dr. Downes what his experience had been in cases of fracture of this kind with dislocation of the semilumar bone and considerable displacement of the fragnents. Whether, under stech conclitions, it would be better to remove the entire row of bones, or only the semilmmar and fragments? Some years ago, Dr. Blake said, he showed a case of fracture of the carpal scaphoid, with dislocation of the fragments, in which an operation had been advised but refused. The result of non-interference was a comparatively stiff wrist, with very little return of power. For at least a year following the accident there was considerable pain on using the wrist, and limitation of motion still persisted.

Dr. Cinsrles H. Peck said he recently saw a patient who about six years ago had fallen from his horse, striking on the extended hand. The case was treated as a sprain, and since the time of the accident the patient had never been entirely free from pain over the carpal scaplioid, and this had interfered with his duties, which were those of a mining engineer. Nothing abnormal could be felt in the wrist, but a radiograpl seemed to confirm the diagnosis of old fracture of the carpal scaphoid.

Dr. Arthur Lyman Fisk said that in the early part of the 
summer he saw a case of fracture of the radius in which the fragments were baclly united, and on attempting to break the umion, there was a sudden snap, which, he believes, must have been due to fracture of the scaphoid. In this instance the accident was produced by liyperextension, while endeavoring to separate the lower fragment of the radius from the upper.

Dr. JoIr $A$. Hartiviele said that a small branch of the radial nerve passed over the radius in the so-called anatomical snuffbox of the wrist, and that pressure upon this point gave rise to considerable pain, even under normal conditions. This fact had recently led him to suspect a fraeture of the carpal scaphoid in a ease which proved to be a simple sprain. The X-ray showed that 10 fracture had occurred.

DR. Gronge A. Wootsey said that Dr. Downes' paper was important in calling attention to an injnry which was now recognized much more frequently than before the introduction of the $\mathrm{X}$-ray. Personally, he could recall but a single case when the diagnosis was made, and in that instance there was a compound fracture of the scaphoicl with dislocation of the semilunar.

Dr. Downrs, in closing the discussion, said that his experience was limited to cases of simple fracture. He had seen no case in which there was either a dislocation or injury of the semilunar. In one case of that claaracter under the care of Dr. L. A. Stimson, an operation land been done for the removal of one or both fragments of the fractured scaphoid. That case had been reported by Dr. Stimson at a meeting of the Society last spring. The injury had occurred in a man who fell thirty feet, fracturing his pelvis, and receiving an anterior dislocation of the semilumar with fracture of the scaphoid, and Dr. Stimson removed the proximal portion of the scaphoid and semilunar bones. The wrist subsequently could not be extended beyond a straight line; flexion was limited to about one-half, and there was considerable radial shortening of the earpus; however, some improvement in motion is taking place and the patient has a fairly uscful hand.

Dr. Downes saicl the point of tenderness in the normal wrist to whieh Dr. Hartwell had referred had bcen mentioned by Codman and Chase, and also by Eisendratl. In cases of fracture the tenderness was not absolutely limited to the snuffbox, but often extencled fairly well over towarcls the inner side of the radius. While the $\mathrm{X}$-ray was the most important aid in the recog- 
nition of this form of fracture, the possible presence of crepitus should not be overlooked.

\section{ACUTE DIVERTICULITIS OF DESCENDING COLON AND SIGMOID PERFORATION.}

Dr. Clarience: A. McWicciams reported the history of a man, 47 years old, who was brought to the Presbyterian Hospital by ambulance on October 4,1907 , at 8 p.... His sickness began four days previously, and prior to that he had been constipated for a week. His previous history was negative. Four days prior to his admission he had a chill in the morning and some cramps it the abdomen, whieh were not loealized. Diring the two following days he was up and about and did not have any medical attention. About 4 A.M. of the morning of admission lie was seized with an excruciating pain in the abdomen, requiring the adininistration of morphine, which relieved him. In the afternoon he vomited for the first time. He could not localize his pain but thought it was more severe on the right side. His temperature on admission was 104.4; pulse, 155, and of poor quality. The abdomen was mueh distended and rigid in all directions. The patient was a very corpulent man, and no mass could be felt. The abdomen was tencler everywhere, but especially so in the suprapubie region and in the right iliae fossa. There was flatness in the right flank, which extended downwarel anteriorly. There was an indistinet fluid wave in the abdomen. Rectal examination was negative. The leneocytosis was 14,000 .

The diagnosis was made of general septic peritonitis due to appendicitis. On opening the abdomen over the appendix by an intermuscular incision, milky fluid under great tension spurted out for a distance of two feet. The intestines were flaked with large masses of fibrin; they were dull and rough, and adherent in places. The pelvis was full of milky fluid, which also gushed from the liver region. The appendix was brought into the wound and was found to be no more inflamed than the remainder of the intestines. The appendix was removed and a small ineision was then made through the middle of the upper part of the right reetus, allowing the escape of a large amount of fluid which was clearer than that in the pelvis. A large quantity of fluid was also found between the liver and diaphragm. The stomach was enormously dilated with fluid; its surface was normal, showing 